\title{
Direct patient reporting of adverse drug reactions: An analysis of spontaneous reports submitted to Malaysian pharmacovigilance centre
}

\author{
Vidhya Hariraj, Zoriah Aziz \\ Department of Pharmacy, Faculty of Medicine, University Malaya, Kuala Lumpur, Malaysia
}

*For correspondence: Email: zoriah@um.edu.my; Tel: +60-379674909

Sent for review: 24 April 2018

Revised accepted: 24 July 2018

\begin{abstract}
Purpose: To evaluate patient adverse drug reaction (ADR) reports in terms of categories by System Organ Class (SOC), suspected products and seriousness.

Methods: The national database was retrospectively searched from 2008 to 2015. ADR reports by patients were included but vaccine-related reports and reports by healthcare professionals were excluded. Eligible reports were analysed descriptively and Chi-square test was used to evaluate the association of various categorical variables with serious ADRs.

Results: Of the total of 75,391 reports screened in the National ADR database for the study period, only $81(0.11 \%)$ were reports from patients, of which $32(40 \%)$ reports involved serious ADRs. The majority of reports was associated with unregistered products or unapproved cosmetics. Half of the reports involved traditional products while cosmetic products constituted another $10 \%$ of the reports. The three main SOCs involved were skin and appendages disorders (26\%), body as a whole (25\%), and central and peripheral nervous system disorders ( $9 \%$ ). A total of 23 out of 47 products tested were adulterated with prescription drugs while 4 cosmetic products exceeded the permitted limit for hydroquinone or mercury. Two factors found to be significantly associated with serious ADRs were product registration status and presence of adulteration.

Conclusion: The findings indicate that patient reporting of suspected ADRs has the potential to add valuable information to pharmacovigilance.
\end{abstract}

Keywords: Adulterants, Patient reporting, Complementary and alternative medicines, Cosmetics, Pharmacovigilance

This is an Open Access article that uses a funding model which does not charge readers or their institutions for access and distributed under the terms of the Creative Commons Attribution License (http://creativecommons.org/licenses/by/4.0) and the Budapest Open Access Initiative (http://www.budapestopenaccessinitiative.org/read), which permit unrestricted use, distribution, and reproduction in any medium, provided the original work is properly credited.

Tropical Journal of Pharmaceutical Research is indexed by Science Citation Index (SciSearch), Scopus, International Pharmaceutical Abstract, Chemical Abstracts, Embase, Index Copernicus, EBSCO, African Index Medicus, JournalSeek, Journal Citation Reports/Science Edition, Directory of Open Access Journals (DOAJ), African Journal Online, Bioline International, Open-J-Gate and Pharmacy Abstracts

\section{INTRODUCTION}

The latest European pharmacovigilance legislation defines direct patient reporting of Adverse Drug Reaction (ADRs) as "submission of an ADR report to the national centre without the intervention of a healthcare professional" [1].
A report is also considered as patient report for cases whereby the health-care professional assisted the patient only in the submission of the report and did not initiate the report, nor provide any additional information or interpretation to the report [2]. The term "consumer reporting" is sometimes used to refer to reporting of ADRs by 
the general public, which includes patients [3]. For the purpose of our study, the term patient reporting was used to mean reports sent by the general public or patients.

For most countries, pharmacovigilance initially began with spontaneous reporting of ADR by healthcare professionals (HCPs) but they are now broadening their scope to include patients or the end users of the medicines to report ADRs. From 10 countries in the 1990s, today, more than 50 countries employ patient reporting systems in pharmacovigilance [4].

Patients provide more details and clearer descriptions of their experiences than health professionals when reporting suspected ADRs [5]. Another important element of patient reporting is that patient self-reports capture the subjective elements of patients' experience and provide impact of ADR on their quality of life which often cannot be transmitted through a HCP [6]. Direct patient reporting is therefore beneficial because it provides direct information to regulators to understand experiences from the primary source without any filtration or delay in submission by healthcare professionals.

In Netherlands, qualitative interviews among patient reporters identified that the main motives for patients to report suspected ADRs were the severity of the condition and the opportunity to share their experiences [7]. Evidence from another study in the United Kingdom (UK) showed that patients report a suspected ADR when they consider the HCP has ignored their concerns [8]. In a large UK study that explored patients' opinions about the importance of being able to report suspected ADRs through the Yellow Card Scheme (YCS) [9], showed that patients believe that reporting would benefit others.

In Malaysia, patient reporting was initiated in 2007. Trained pharmacists analyse the ADR reports received according to WHO-UMC's standardised case causality assessment [10] and if needed, a sample is obtained from the reporter for quality testing. This study aimed to describe the characteristics of the ADR reports from patients in terms of types of products, system organ classes (SOC) involved and seriousness of ADRs.

\section{METHODS}

\section{Study setting}

The Malaysian Pharmacovigilance database is the central database for all suspected spontaneous ADR reports in Malaysia. It contains all ADR reports from members of the healthcare system in government and private health facilities as well as pharmaceutical companies and patients. Being a national repository managed by the National Pharmacovigilance Centre, within the Ministry of Health, it is governed by the jurisdiction of the Malaysian Control of Drugs and Cosmetics Regulation 1984. The minimum information required for a valid ADR report are: reporter identification, patient identification, at least one suspected active substance/medicinal product, and at least one suspected ADR [11].

\section{Study design}

The study was a retrospective analysis of spontaneous ADR reports from the National ADR database from year 2008 to 2015 .

\section{Operational definitions and assessments.}

ADRs were classified by System Organ Class according to the WHO Adverse Reactions Terminology (WHO-ART). According to the International Conference on Harmonisation (ICH) E2A classification [12], a serious ADR is defined as "any untoward medical occurrence that, at any dose, results in death, is life-threatening, requires hospitalisation or prolongation of existing hospitalisation, results in persistent or significant disability, caused congenital anomaly or birth defect or an important medical event." As part of the WHO international drug monitoring programme, the WHO-UMC causality assessment system for evaluation of ADR reports is applied for all ADR reports. As patients have the tendency to report any ADR caused by any type of product, where necessary, the products were classified according to the Malaysian Drug Registration Guidance Document [13].

\section{Data extraction}

Only reports from patients for the period January 2008 to December 2015 were extracted from the national database. For each ADR report, the data recorded included age, sex, indication, ADR description, system organ class of ADR reaction, date and time of reaction onset and end, date of report, suspected drug, pharmacological group of drugs, concomitant disease, concomitant medications, outcome, extent of ADR and recovery after treatment.

Reports related to vaccine or adverse events following immunization (AEFI) were excluded. To prevent reporting bias, HCPs who used forms 
specifically for patients to report ADRs were also excluded.

\section{Data analysis}

All analysis was conducted using IBM SPSS version 20 (SPSS Inc., Chicago IL, USA). For categorical data such as seriousness of ADRs, categories of ADRs by SOC and product groups, data were presented as absolute numbers or percentages. Pearson Chi-squared test of independence was used to evaluate the association of various categorical variables with serious ADRs. Level of significance was set at $p$ $<0.05$.

\section{Ethics approval}

As this study was non-intervention, no consent from patients or doctors was required. The information from the database does not contain name of patient or reporter. Approval to conduct the study and access the system were obtained from the National Institute of Health and Medical Research and Ethics Committee in the Ministry of Health (no. NMRR-16-253-29412). The study was also conducted in accordance with International Ethical Guidelines for Health-related Research Involving Humans [14].

\section{RESULTS}

\section{Characteristics of patients reporting ADRs}

Out of 101,957 ADR reports in the National ADR database, 75,391 reports were for the period 2008 to 2015. After screening and excluding vaccine-related reports and reports from HCPs. Only $81(0.11 \%)$ reports were from patients and thus eligible to be analysed.

A higher proportion of female, Malay race and those aged between 41 to 60 years old reported ADR (Table 1). All methods to report an ADR were used at least once, though the majority preferred the patient reporting form designed specifically for patients. About $40 \%$ of the reports involved serious ADRs.

Almost all the ADR reports were accompanied with additional information such as photographs of the product or the ADRs (e.g. skin conditions), product label, purchase invoice and medical reports.

\section{ADR reports according to System Organ Classes (SOCs)}

For SOC classification, the WHO-ART was applied as this classification was used by the national centre in its routine ADRs reporting to WHO-UMC. In terms of SOC, Skin and Appendages Disorders was the most commonly reported disorders followed closely by Body as a Whole- General Disorders. The other three frequently reported classes were central and peripheral nervous system disorders, metabolic and nutritional, and psychiatric disorders (Figure 1).

Table 1: Characteristics of patients who reported to the National ADR Centre and method of reporting

\begin{tabular}{lc}
\hline Variable & $\mathbf{N}=\mathbf{8 1},(\%)$ \\
\hline Gender & \\
Male & $25(30.9)$ \\
Female & $56(69.1)$ \\
Race & \\
Malay & $42(51.9)$ \\
Chinese & $30(37.0)$ \\
Indian & $4(4.9)$ \\
Others & $5(6.2)$ \\
Reporter type & \\
Patient & $70(86.4)$ \\
Representative & $11(13.6)$ \\
Age group (years) & \\
Less than 20 & $8(9.9)$ \\
21-40 & $16(19.8)$ \\
41-60 & $31(38.3)$ \\
61 and above & $12(14.8)$ \\
Missing data & $14(17.2)$ \\
Concomitant drugs & \\
Yes & $15(18.5)$ \\
Unknown & $66(81.5)$ \\
Seriousness & \\
Yes & $32(39.5)$ \\
$\quad$ No & $49(60.5)$ \\
Report type & \\
Patient Form & $52(64.2)$ \\
Healthcare professional form & $10(12.3)$ \\
Letter & $8(9.9)$ \\
Online & $6(7.4)$ \\
Others (phone call, walk in) & $5(6.2)$ \\
\hline
\end{tabular}

\section{Category of products involved, ADR seriousness and types of adulterants}

The main category of products reported with 39 $(48 \%)$ reports was Traditional products (Table 2 ) with half of these reports associated with serious ADRs. However, only $5(13 \%)$ of these were registered products. A total of $47(58 \%)$ products with available samples were sent for laboratory testing and 27 (33 \%) were found to be noncompliant. They were either adulterated with prescription medicines (23 products) or cosmetic products which exceeded permitted limit for hydroquinone and mercury (4 products). Examples of adulterants found include sildenafil, dexamethasone, phentermine and sibutramine. 


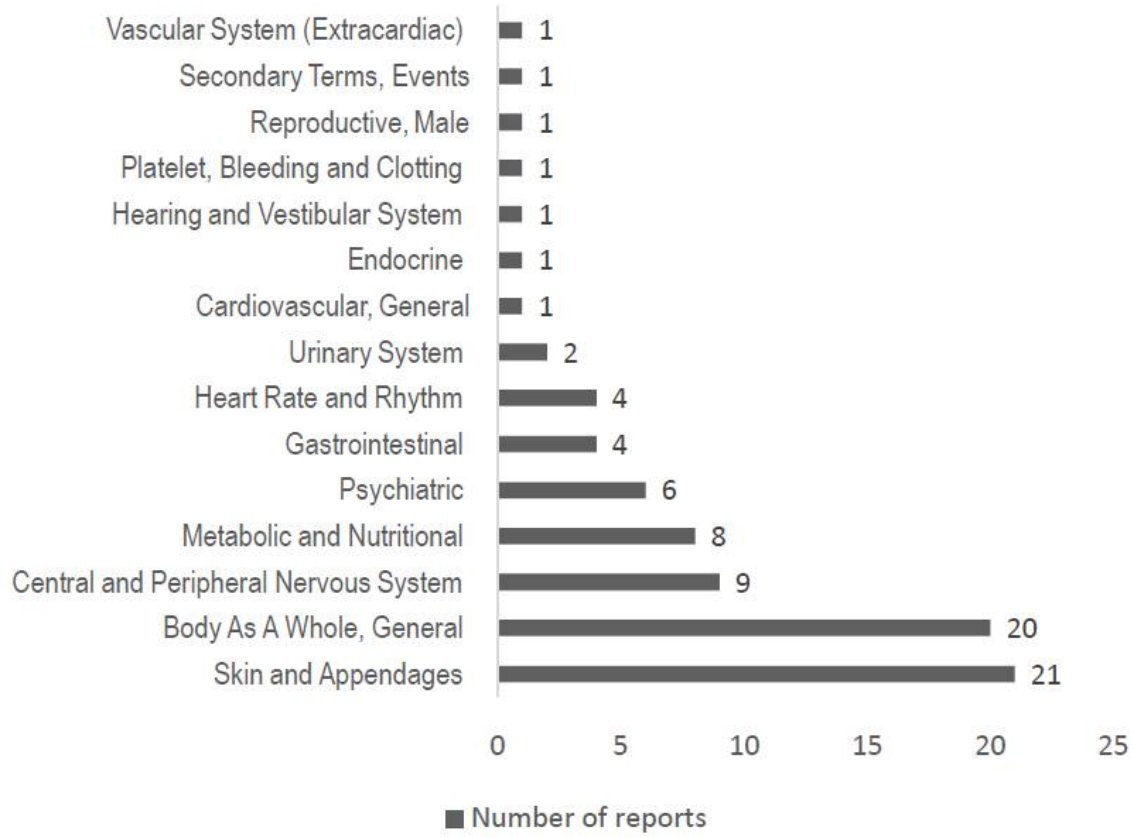

Figure 1: Adverse drug reactions according to the disorders of system organ class reported by patients

Table 2: Category of products involved and ADR seriousness

\begin{tabular}{lcccc}
\hline $\begin{array}{l}\text { Products } \\
\text { (N=81 }\end{array}$ & $\begin{array}{c}\text { Number of } \\
\text { reports }\end{array}$ & $\begin{array}{c}\text { Number of } \\
\text { unregistered } \\
\text { or } \\
\text { unapproved } \\
\text { products }\end{array}$ & $\begin{array}{c}\text { Number of } \\
\text { products tested } \\
\text { and found } \\
\text { adulterated or } \\
\text { noncompliant* }\end{array}$ & $\begin{array}{c}\text { Serious } \\
\text { ADR }\end{array}$ \\
\hline Prescription & 14 & 0 & 0 & 2 \\
Traditional medicine & 39 & 34 & 20 & 21 \\
Health supplement & 7 & 1 & 1 & 0 \\
Over the counter (OTC) & 5 & 0 & 0 & 1 \\
Cosmetic & 9 & 4 & 4 & 4 \\
Unclassifiable & 7 & 7 & 2 & 4 \\
\hline
\end{tabular}

${ }^{\star}$ Exceeded limit for substances permitted in cosmetics

Two factors found to be significantly associated with serious ADRs were product registration status $\left[X^{2}(1, N=811=8.76, p=0.03]\right.$ and presence of adulteration $\left[X^{2}(6, N=81)=21.64, p=0.001\right]$.

\section{DISCUSSION}

The study describes the characteristics of ADR reports from patients thus provides useful information in terms of SOC of suspected ADRs, product categories, seriousness of ADRs and results of laboratory testing. Although the sample was small, the patients reported serious ADR that was significantly shown to be associated with unregistered and adulterated products. Thus it seems that patients can provide valuable information for reliable drug safety monitoring in the country. The key area for improvement is increased awareness in ADR reporting among patients. This will provide an avenue for patients to play an active role and contribute to pharmacovigilance activities. Patients as end- users need to be made aware that their feedback is valued and necessary.

Despite exceeding the target of more than 200 ADR spontaneous reports per million population set by WHO, rate of ADR reporting by patients is still low in Malaysia. Less than one percent of the ADR reports in the national database were reports by patients. A 2013 study in Portugal also showed similar findings whereby only $1.4 \%$ of the total reports were by patients [15]. To date, the NPRA has introduced an online reporting system for patients in Malaysia. The introduction of an online system would surely benefit patient pharmacovigilance towards direct patient reporting and faster transmission of information. Countries with an online reporting system for patients have the highest reporting rate [4]. The study findings advocate more patient-oriented initiatives to complement the pharmacovigilance system. Encouraging patients to report can increase reporting rates and bridge the underreporting gap. 
Country based retrospective studies analysing spontaneous ADR reports databases have been conducted in the UK, Netherlands and Denmark [16-18]. In the UK study, the researchers compared ADR reports of patient with HCPs and found that HCP reports had a higher proportion of reports that caused serious ADRs. Unlike this study which did not directly compare reports of HCPs with those from patients, it was found that patients tend to report serious ADR. This was similar to a study done in Europe among consumers who reported ADRs on nervous system medications [19]. Also in the Netherlands, patients reported a significantly higher number of life threatening ADRs (5.2 vs $2.7 \%$ ) and disability (2.3 vs $0.4 \%$ ) compared to HCPs [17].

In a systematic review examining factors influencing ADR reporting by patients, among the main reasons identified were to prevent $A D R$ and to share ADR information [20]. Based on previous findings [21], it can be speculated that patients report serious ADRs probably because they are motivated by being able to do good for others and the belief that reporting can contribute to the current knowledge.

When patients submit reports to the centre, there is an opportunity of early detection of safety issue resulting in quicker action taken towards patient safety. In Malaysia, if a registered product was tested and found adulterated, it will be tabled to the Malaysian Drug Control Authority for cancellation of the registration and followed by a press release statement to alert the public of the safety concern. For unregistered products found adulterated, cases are forwarded to the Enforcement Agency within the Ministry of Health for further action. The NPRA also maintains a list of these products on the website for quick reference by the public. All the actions taken are due to reports from patients which shows that patients can contribute to signal detection and drug safety. Similar findings with regards to signal detection have been shown in the UK and Netherlands [22,23]. Although the numbers of patient ADR reports in the Malaysian database was less than $1 \%$ of the total reports, but the impact has been profound.

The characteristics of patients that use traditional medicines resonates with a previous Malaysian study which examined the prevalence and predictors of herbal medicines' use [24]. The study identified females of Malay race to be the primary users thus they were more likely to experience ADRs. Female ADR reporters have been found to represent around $60 \%$ of all reports in a systematic review [25]. Similarly, in this study the majority of the reports came from female patients. Consistent with a previous study involving 15 countries [5], this study also found that patients provided more detailed description of the burden of ADR in their reports. Although most ADRS cases could not be medically confirmed, reports show that patients can contribute to ADR reporting and are willing to provide as much information as possible.

The most common SOC reported among patients in Malaysia was Skin and Appendages Disorders, followed by Body as a Whole, General Disorders and Central and Peripheral Nervous System. However, these findings differ from findings of other countries. In a systematic review examining the value of patient reporting in pharmacovigilance, it was reported that the five most frequently reported SOC by patients were Nervous system disorders, psychiatric disorders, gastrointestinal disorders, musculoskeletal disorders and general disorders/administrationsite conditions [25]. A study in Netherlands also reported that the main SOC involved was the nervous system disorders [17]. Perhaps the difference could be related to the level of education and ADR knowledge between Malaysian patients and those from developed countries, as most Malaysian patients recognise a skin reaction as an allergy but are not aware of other types of ADR reactions. In a survey of awareness and confidence to report ADRs among the public in Malaysia, it was found that the awareness level of ADR reporting to the national centre was low although they were confident to report an ADR [26]. More research needs to be conducted to understand the ability of patients to recognise different types of ADRs and report them. However, this findings were similar to another retrospective study conducted in Malaysian paediatric population whereby skin related reactions represented $20 \%$ of the total reports in that population [27]. In a systematic review by Inacio et al [25], the four most frequently reported suspected drugs by patients were pregabalin, simvastatin, sex hormones, and SSRIs while for this study, the suspected drugs involved were mostly traditional products. It was also alarming to see that many of these products are unregistered and adulterated with substances considered as conventional medicines. This highlights the need to educate the public on the use of traditional products because of the potential of serious ADRs.

The ADR reports by patients need to be interpreted cautiously as the ADRs reported are not ascertained by a HCP. In cases like this, a feedback mechanism to patients is essential by the national regulatory agency to ensure that patients stop taking the product and seek 
medical attention. Currently the national centre provides an official feedback for every patient report. With increasing reporting rates, more resources will be required. As most of the reports were also serious cases, it is crucial that ADR education and awareness programmes or campaigns include first aid management of an ADR encounter. Patients should not only be made aware of the ADR and to report but also to stop all medications and seek treatment immediately.

\section{Limitations of the study}

As this study involved a database that employed a spontaneous reporting system, it suffers from several limitations as highlighted in previous literature [28]. The limitations include reporting biases, under-reporting of ADRs, inability to determine incidence rate or prevalence of any ADRs reported and incomplete reports. The patient reports were not compared with ADR reports from HCPs as the number of patient reports was too small.

\section{CONCLUSION}

The findings of this study show that patients report mainly serious ADRs associated with the use of unregistered traditional products thus reinforcing the fact that patients can serve as a complementary source to strengthen the pharmacovigilance system in Malaysia. Future research needs to be conducted on ways to promote and educate patients on ADR reporting as well as encouraging healthcare professionals to empower patients.

\section{DECLARATIONS}

\section{Acknowledgement}

The authors would like to extend their appreciation to the Director General of Health and pharmacovigilance staff of National Pharmacy Regulatory Agency, Ministry of Health, Malaysia. This work was supported by University Malaya, Kuala Lumpur study grant (No. PG1252014A).

\section{Conflict of interest}

The authors declare that no conflict of interest is associated with this work.

\section{Contribution of authors}

We declare that this work was done by the authors named in this article and all liabilities pertaining to claims relating to the content of this article will be borne by the authors. Vidhya Hariraj collected, analysed the data and wrote the first draft of the manuscript. Zoriah Aziz advised on methodology, checked the data extraction, reviewed the analyses and edited the manuscript. Both authors read and approved the manuscript for publication.

\section{REFERENCES}

1. Regulation No $1235 / 2010$ of the European Parliament and of the Council of 15 December 2010. Off J Eur Union.

2. World Health Organization. Safety Monitoring of Medicinal Products. Reporting system for the general public [Internet]. 2012 [cited 2018 Feb 22]. Available from: http://www.who.int/medicines/areas/quality_safety/ safety_efficacy/EMP_ConsumerReporting_web_v2.pdf

3. World Health Organization. Safety Monitoring of Medicinal Products. Guidelines for setting up and running a Pharmacovigilance Centre [Internet]. 2000 [cited 2018 Feb 22]. Available from: http://apps.who.int/ medicinedocs/en/d/Jh2934e/

4. Margraff F, Bertram D. Adverse drug reaction reporting by patients: an overview of fifty countries. Drug Saf 2014; 37(6): 409-419.

5. Herxheimer A, Crombag R, Alves TL. Direct Patient Reporting of Adverse Drug Reactions: A Fifteen-Country Survey \& Literature Review. Health Action International (HAl) [Internet]. 2010 [cited 2018 Feb 22]. Available from: http://consumers.cochrane.org/sites/ consumers. cochrane.org/files/public/uploads/10\%20May \%202010 \%20Report\%20Direct\%20Patient\%20Reporting\%20of\% 20ADRs.pdf.

6. Basch E. The missing voice of patients in drug-safety reporting. N Engl J Med 2010; 362: 865-869.

7. Harmark L, Puijenbroek E, Grootheest K. Longitudinal monitoring of the safety of drugs by using a web-based system: the case of pregabalin. Pharmacoepidemiol Drug Saf 2011; 20: 591-597.

8. Avery AJ, Anderson C, Bond CM, Fortnum H, Gifford A, Hannaford PC, Hazell L, Krska J, Lee AJ, McLernon DJ et al. Evaluation of patient reporting of adverse drug reactions to the UK "Yellow Card Scheme": literature review, descriptive and qualitative analyses, and questionnaire surveys. Health Technology Assessment. 2011; 15(20): 1-234, iii-iv

9. Anderson C, Krska J, Murphy E, Avery A. The importance of direct patient reporting of suspected adverse drug reactions: a patient perspective. $\mathrm{Br} J$ Clin Pharmacol 2011; 72: 806-822.

10. The use of the WHO-UMC system for standardised case causality assessment. .[Internet] 2018 [cited 2018 Feb 22] Available from: http://www.who.int/medicines/ 
areas/quality_safety/safety_efficacy/WHO causality_ass essment.pdf

11. International Conference on Harmonisation Of Technical Requirements For Registration Of Pharmaceuticals For Human Use: Post-Approval Safety Data Management: Definitions And Standards For Expedited Reporting E2D Current Step 4 version [Internet]. 2003 [cited 2018 Feb 22] Available from:http://www.ich.org/products/guide lines.html

12. International Conference on Harmonisation Of Technical Requirements For Registration Of Pharmaceuticals For Human Use: Clinical Safety Data Management: Definitions And Standards For Expedited Reporting E2A Current Step 4 version [Internet]. 1994 [cited 2018 Feb 22] Available from: http://www.ich.org/products/guide lines.html

13. National Pharmaceutical Regulatory Agency, Ministry of Health (MOH). Drug Registration Guidance Document. [Internet] 2016 [updated Sep 2017; cited 2018 Feb 22] Available from: http://npra.moh.gov.my/index.php/drugregistration-guidance-document-drgd

14. International Ethical Guidelines for Health-related Research Involving Humans. Fourth edition. Geneva. Council for International Organisations of Medical Sciences (CIOMS); 2016.

15. Matos $C$, van Hunsel $F$, Joaquim J. Are consumers ready to take part in the Pharmacovigilance System?-a Portuguese preliminary study concerning ADR reporting. Eur J Clin Pharmacol 2015; 71(7): 883-890.

16. McLernon DJ, Bond CM, Hannaford PC, Watson MC, Lee AJ, Hazell L, Avery A. Adverse drug reaction reporting in the UK: a retrospective observational comparison of yellow card reports submitted by patients and healthcare professionals. Drug Saf 2010; 33(9):775788.

17. de Langen J, van Hunsel F, Passier A, de Jong-van den Berg L, van Grootheest K. Adverse Drug Reaction Reporting by Patients in the Netherlands. Drug Saf 2008; 31(6): 515-524

18. Aagaard L, Nielsen LH, Hansen EH. Consumer Reporting of Adverse Drug Reactions. A Retrospective Analysis of the Danish Adverse Drug Reaction Database from 2004 to 2006. Drug Saf 2009; 32(11): 1067-1074.

19. Aagaard L, Hansen EH. Adverse drug reactions reported by consumers for nervous system medications in Europe 2007 to 2011. BMC Pharmacol Toxicol. 2013; 14: 30.

20. Al Dweik $R$, Stacey $D$, Kohen $D$, Yaya S. Factors affecting patient reporting of adverse drug reactions: a systematic review. Br J Clin Pharmacol 2017; 83(4): 875-883.

21. Harmark L, Lie-Kwie M, Berm L, et al. Patients' motives for participating in active post-marketing surveillance. Pharmacoepidemiol Drug Saf 2013; 22(1): 70-76.

22. Hazell L, Cornelius V, Hannaford P, Shakir S, Avery AJ. How Do Patients Contribute to Signal Detection? A Retrospective Analysis of Spontaneous Reporting of Adverse Drug Reactions in the UK's Yellow Card Scheme. Drug Saf 2013; 36(3): 199-206

23. van Hunsel F, Talsma A, van Puijenbroek E, de Jong-van den Berg $L$, van Grootheest $K$. The proportion of patient reports of suspected ADRs to signal detection in the Netherlands: case-control study. Pharmacoepidemiol Drug Saf 2011; 20: 286-291.

24. Aziz Z, Tey NP. Herbal medicines: Prevalence and predictors of use among Malaysian adults. Compl Ther Med 2009; 17: 44-50.

25. Inacio $P$, Cavaco A, Airaksinen M. The value of patient reporting to the pharmacovigilance system: $A$ systematic review. Br J Clin Pharmacol 2017; 83(2):227-246.

26. Hariraj V, Aziz Z. Patient Reporting of Adverse Drug Reactions (ADRs): A Survey of Public Awareness and Predictors of Confidence to Report. Mar 1, 2018, DOI: 10.1177/2168479017745025

27. Rosli R, Ming LC, Abd Aziz N, Manan MM. A Retrospective Analysis of Spontaneous Adverse Drug Reactions Reports Relating to Paediatric Patients. PLoS ONE 2016; 11(6): e0155385

28. Hazell L, Shakir SAW. Under-reporting of adverse drug reactions - A systematic review. Drug Saf 2006; 29(5): 385-396. 